\title{
Concepções e Práticas do Trabalho e da Gestão de Equipes Multidisciplinares na Saúde
}

\author{
Concepts and Practices of Work and Multidisciplinary Team \\ Management in Health Sevice
}

\author{
Lucimara Alves Silva \\ Professora, Instituto Federal de Educação, Ciência e Tecnologia da Bahia - Salvador - BA, Brasil. E-mail: silvalucimara@uol.com.br \\ Jair Nascimento Santos \\ Professor, Universidade Salvador e Universidade Estadual de Feira de Santana - Salvador - BA, Brasil.E-mail: jair.santos@unifacs.br
}

\section{Resumo}

Este trabalho trata do seguinte objetivo: conhecer as concepções e a prática de trabalho em equipe multidisciplinar sob a ótica dos gestores e dos membros das equipes. Para o desenvolvimento da pesquisa, foi criado o seguinte problema: como se desenvolve o trabalho e a gestão da equipe multidisciplinar de saúde em organizações hospitalares? O estudo foi desenvolvido com profissionais de nível superior de dois hospitais. Verificou-se que na prática de gestão existem dissonâncias em relação ao discurso quando não há o reconhecimento da relação de poder ou na ausência de uma política estruturada que reflita um tratamento multidisciplinar do trabalho em equipe.

Palavras-chave: Trabalho em equipe. Equipe multidisciplinar de saúde.

\section{INTRODUÇÃO}

A maneira com a qual as organizações hospitalares são geridas define a especificidade de seus serviços, o quantitativo e a especialidade dos profissionais de saúde que compõem as equipes multidisciplinares e a forma como o processo de trabalho se desenvolve. Então, pode-se afirmar que pela própria essência humana e pela rápida transformação das suas necessidades no processo saúde-doença, o indivíduo impulsiona os serviços de saúde na busca de novas formas de atendê-los.

\section{Abstract}

This study addressed the following objective: to know the concepts and the practice of multidisciplinary team work from the perspective of managers and team members. The problem of the research was: how to develop and to manage the work of the multidisciplinary health care team in the hospital organizations? The study was developed with toplevel professionals of two hospitals. It was found that in the management practice there are dissonances in relation to discourse when there is no recognition of the power relations or in the absence of a structured policy that reflects a multidisciplinary team work treatment.

Key words: Team work. Multidisciplinary health care team.

Nesse contexto, Ciampone e Peduzzi (2000) destacam que no processo de produção em saúde, a denominação equipe sempre fará referência a uma situação de trabalho. Nesse sentido, o tipo de serviço desenvolvido para esse fim sempre se fará em situações que envolvem dimensões humanas que demandam necessidades de saúde e que em algumas situações envolvem dor, sofrimento e até mesmo a morte.

Peduzzi (1998), a partir dos estudos de Campos (1992b), ressalta que os serviços de saúde, que na sua organização possui como estratégia a estruturação das 
equipes, devem considerar o rompimento da divisão do processo de trabalho e responsabilizar cada equipe pela organização e planejamento de seu trabalho, assim como de problemas advindos da sua rotina.

No que diz respeito à constituição das equipes de saúde, Matumoto et al. (2005) com base nas contribuições de Campos (1997) e Fortuna (1999; 2003), alertam que as equipes não se processam pela simples presença das diversas categorias profissionais, mas sim pela interação efetiva das diversas disciplinas e saberes, agindo como elemento integrador de seus membros.

No entanto, Scharaiber et al. (1999) ressaltam como importante fator a ser considerado nessas equipes o fato de que os membros que as constituem trazem uma autonomia técnica, com profissões cujas autoridades são desiguais, o que podem gerar situações de poder, levando a tensões internas, principalmente por parte de alguns profissionais.

Nesse sentido, no que diz respeito à relação de poder no âmbito das equipes de saúde em organizações hospitalares, essa relação torna-se mais evidente a partir da forma como se processa a produção dos serviços médicos, pois, conforme Oliveira e Collet (2000), o atual modelo de assistência oferecido somente é constituído a partir do diagnóstico e tratamento instruídos pelo parecer do profissional médico.

Assim, este artigo tem como objetivo: conhecer as concepções e a prática de trabalho em equipe multidisciplinar sob a ótica dos gestores e dos membros das equipes, por entender que o trabalho na saúde desenvolvido em nível hospitalar está voltado para atender pacientes internados, o que demanda nesse nível de atenção uma maior complexidade dos serviços.

Para tanto, é apresentado um recorte teórico estudado, atendo-se a conteúdos como: trabalho em equipe; peculiaridades das atividades em saúde e equipe multidisciplinar de saúde; metodologia; resultados e conclusões.

\section{Trabalho em Equipe}

Uma das competências mais discutidas e valorizadas pelas organizações é o trabalho em equipe. Peduzzi (1998) elaborou uma tipologia do trabalho em equipe, apontando a existência de duas modalidades do trabalho em equipe: a equipe agrupamento $e$ a equipe integração. A primeira caracteriza-se pela justaposição das ações e agrupamentos dos agentes e a segunda constituída na possibilidade de articulação das ações $e$ interação dos agentes.

No entanto, para que a equipe tenha objetivos comuns e para que eles sejam alcançados, Souza, Campos e Ramos (2001), a partir dos estudos de Deming (1990), alertam sobre a importância das lideranças, uma vez que elas são responsáveis por estimular a equipe no alcance de seus objetivos; assim como em promover um ambiente que propicie conhecimento.

Para Pinho (2006), o trabalho em equipe é apontado como estratégia para promover novas visões do trabalho, no sentido de equacionar processos em que cada membro possa dimensionar suas ações, avaliando sempre sua participação enquanto integrante da equipe e priorizando a comunicação para uma avaliação contínua do trabalho.

Nesse sentido, Riccardi et al. (2009) alertam que o mundo contemporâneo sujeita empresas e trabalhadores a promoverem ágeis e constantes adaptações. A capacidade de trabalhar em equipe torna-se um dos requisitos exigidos, a competição e o individualismo dão lugar a posturas mais cooperativas, responsáveis e participativas.

\subsection{Peculiaridades das Atividades em Saúde}

Inserido no setor terciário da economia, o trabalho na saúde se diferencia dos demais, pelo fato de lidar direta ou indiretamente com a vida humana nas mais diversas situações, e, nesse caso, qualquer falha pode incorrer em fragilidades graves ou em erros fatais.

Outra característica do trabalho em saúde apontado por Leopardi (1999) e Pires (2000), citado por Calomé (2005) é que o seu desenvolvimento acontece, principalmente, a partir da presença de diversas categorias profissionais que compõem a equipe multidisciplinar de saúde. Isso ocorre porque a expectativa desse trabalho parte da visão de que é preciso atender não apenas às necessidades individuais de um único paciente, mas sim às necessidades de uma coletividade. Constituindo-se, portanto numa prática de trabalho coletivo.

Matumoto et al. (2005), a partir dos estudos de Mendes Gonçalves (1992) e Merhy (2002) quanto ao 
trabalho em saúde, afirmam que o trabalhador ao atuar diretamente sobre os problemas de saúde, contribui para o desenvolvimento do vínculo de confiança entre trabalhador e paciente favorecendo a sua recuperação e estimulando o autocuidado. Nesse sentido, Merhy (1997) destaca a importância da estruturação e do gerenciamento dos processos de trabalho nos serviços de saúde, e, ainda mais, como os trabalhadores da saúde estão desenvolvendo e percebendo o seu trabalho.

Como importante elemento para consolidação desse processo, Mendes (1999) ressalta a importância da formação acadêmica dos profissionais de saúde, que desde o início do século XX voltou-se para um modelo fragmentador e individual. Sobre esse aspecto, Gariglio e Radicchi (2008) ressaltam a importância dos serviços de saúde para consolidar habilidades e competências na formação dos novos profissionais e acreditam no trabalho como fonte e lugar de aprendizagem e de construção de sujeitos autônomos

\subsection{Trabalho em Equipe na Saúde}

O trabalho em equipe na saúde torna-se importante no atendimento às necessidades e aos problemas de saúde humana, uma vez que as pessoas nem sempre podem ser atendidas por uma única especialidade $e$ tampouco individualmente.

Para Peduzzi (2001), a proposta do trabalho em equipe tem sido veiculada como estratégia para enfrentar o intenso processo de especialização na área da saúde. Pode-se verificar, no entanto, que a realidade entre a teoria e a prática da existência efetiva dessa modalidade de trabalho nas organizações de saúde se configurará a partir da forma com que os serviços são efetivamente estruturados e oferecidos; uma vez que a comunidade demanda das organizações a oferta de serviços que preze cada vez mais pela qualidade e pelo bem-estar do paciente.

Dentro desse processo, Pinho (2006, p. 71) destaca que, quando se trata da formação de equipes na área de saúde, são apontadas algumas especificidades: "[...] dominância de um discurso particular, resultando na exclusão de outro e falta de confiança inter e multidisciplinar fruto de relações de poder entre as profissões". Para Schraiber et al. (1999), o trabalho em equipe na saúde é aquele realizado levando-se em consideração não apenas as especificidades de cada saber técnico, mas sim o que produz consensos para atender à necessidade específica de cada paciente.

Nesse sentido, Peduzzi (2001) e Scharaiber et al. (1999) ressaltam que o trabalho em equipe não pretende desconsiderar as especificidades dos trabalhos, pelo contrário, esse trabalho precisa ser compartilhado $e$ as diferenças técnicas devem ser entendidas como fator facilitador para a divisão do trabalho com vista à qualidade dos serviços prestados. Sobre esse aspecto, Schraiber et al. (1999) afirmam que o trabalho em equipe é o que se compartilha, negociando as distintas necessidades de decisões técnicas. Devendo para tanto, considerar as bases distintas de julgamento e a tomada de decisões dos profissionais quanto aos cuidados que serão prestados pela equipe.

Portanto, para Matumoto et al. (2005, p. 13), torna-se imprescindível que cada organização e cada serviço de saúde identifiquem suas especificidades, realidades e necessidades no sentido de contribuir ativamente como espaço integrador. Ainda para Matumoto et al. (2005) é necessário evidenciar que o tipo de trabalho desenvolvido na saúde, é considerado um trabalho vivo, concordando com Merhy (1997), portanto, ele é desenvolvido essencialmente por seres humanos, e por mais que existam elementos facilitadores ao seu desenvolvimento, não existem equipes perfeitas, assim como o trabalho desenvolvido por essa equipe não conseguirá se processar integralmente por todo o tempo.

No que diz respeito à integração dos cuidados na atenção à saúde, pressupõe-se que seja um trabalho técnico planejado em equipe, com base em situações reais que atendam, de forma continua, às necessidades das pessoas que são acometidas por patologias que causem dor e sofrimento. (HARTZ; CONTANDRIOPOULUS, 2004)

Para Schairber et al. (1999), a articulação das ações visa alinhar as diversas formas de executar o trabalho, próprio de cada especialidade, uma vez que cada uma delas tem suas especificações, atuações $e$ seus saberes. Ainda baseado no conceito de equipe trazido por Peduzzi (1998) quanto à interação dos agentes, ela ressalta que esse conceito vai além da conexão dos saberes e de conhecimentos trazidos por cada membro, a autora pressupõe uma forma de comunicar-se na qual a equipe agregue valores $e$ interesses. 
Diante da prática do trabalho em saúde, coaduna-se com a autora, pois a experiência mostra a necessidade de interação para que a equipe construa processos de comunicação que possam agregar valores individuais e pessoais trazidos por cada paciente, de modo a refletir as suas necessidades reais e a prática do trabalho da equipe, trabalho que deve ser avaliado sempre que se fizer necessário.

\subsubsection{Equipe Multidisciplinar de Saúde}

Para que os objetivos deste trabalho sejam alcançados de forma clara, torna-se necessário tecer algumas considerações sobre multidisciplinaridade e interdisciplinaridade para melhor entender o caminho de construção das equipes multidisciplinares de saúde. Nesse sentido, para Feuerwerker e Sena (1999), o trabalho em equipe multidisciplinar implica construções de novas práticas e saberes, portanto, não se evidencia apenas por meio da interação democrática.

É nesse contexto que o trabalho em saúde produzido em equipe surge como proposta de rompimento de um modelo assistencial, marcado pela

[...] fragmentação da assistência, pela consideração do corpo biológico como objeto de trabalho, pela centralidade das ações nos atos médicos e medicalizadores. (FORTUNA et al., 2005, p. 263)

Para os autores Severo e Seminotti (2010), esse novo olhar no contexto do processo de trabalho em saúde rompe com a visão do trabalho fragmentado $e$ descontextualizado, buscando construir com o outro um trabalho integral como membro da equipe, com o usuário e com o sistema no qual está inserido. No entanto, essas não são mudanças fáceis de processarem, uma vez que estão envolvidas dimensões relacionadas tanto aos trabalhadores quanto aos serviços de saúde.

Nesse sentido, Severo e Seminotti (2010) ressaltam que a visão verticalizada de gestão não permite que os trabalhadores vivenciem a sua autonomia como agentes. Em contrapartida, os modelos de gestão que contemplam colegiados espaços de coparticipação permitem que os trabalhadores vivenciem suas experiências de forma responsável, porém com autonomia.
Contribuindo para a integralidade no interior das instituições, a equipe multidisciplinar de saúde deve ser percebida como elemento facilitador desse processo através da prática de um trabalho interprofissional e interdisciplinar proporcionado pelo conjunto de saberes, de conhecimentos e de experiências trazido por cada um. (SEVERO; SEMINOTTI, 2010)

No entanto, Matos, Pires e Campos (2009, p. 846) ressaltam que, ao analisar as relações de trabalho no interior das equipes multidisciplinares, deve-se considerar como acontece o processo de trabalho e qual a compreensão da equipe acerca de seus componentes (finalidade, objeto, instrumentos, força de trabalho) com objetivo de obtenção dos resultados.

\section{Metodologia}

Para o desenvolvimento do presente artigo, objetivando responder ao problema e alcançar os objetivos propostos quanto à realidade vivenciada pelos profissionais de saúde que desenvolvem seu trabalho em equipe multidisciplinar, adotou-se a abordagem qualitativa.

\subsection{Caracterização da Pesquisa}

Neste artigo, pretende-se divulgar e socializar com a comunidade cientifica os resultados da pesquisa sobre o trabalho da equipe multidisciplinar de saúde e sua gestão em organizações hospitalares, para tanto, foi realizado um estudo descritivo e exploratório de abordagem qualitativa, no qual se buscou investigar o seguinte problema: "como se desenvolve o trabalho e a gestão da equipe multidisciplinar de saúde em organizações hospitalares?”.

\subsection{Instrumento de Coleta de Dados}

Neste estudo, o instrumento de coleta de dados utilizado foi a entrevista guiada por um roteiro semiestruturado composto de perguntas abertas. Foi utilizado ainda um Roteiro para levantamento de dados sociodemográficos para todos os profissionais de saúde e gestores com perguntas fechadas para caracterização dos sujeitos da pesquisa. 


\subsection{Sujeitos da Pesquisa}

Os sujeitos da investigação foram os profissionais de saúde de nível superior do quadro funcional de uma organização hospitalar e que fazem parte da equipe multidisciplinar das unidades de internação: Clínica Médica Cirúrgica (CMC) e Unidade de Terapia Intensiva (UTI); assim como os profissionais gestores dessas unidades, campo desta investigação, que estavam em pleno exercício profissional e que aceitaram participar da pesquisa.

No hospital A, a pesquisa empírica foi realizada com os profissionais da unidade CMC I. As categorias profissionais que participaram da entrevista foram: farmacêutico(a), fisioterapeuta, enfermeiro(a) e nutricionista.

Já no hospital B, a pesquisa foi realizada com os profissionais da UTI geral adulta. As categorias profissionais que participaram da entrevista foram: assistente social, fisioterapeuta, enfermeiro(a), médico(a) e psicólogo.

No total, participaram do estudo 13 profissionais, o anonimato foi elemento preservado durante toda a pesquisa. Para tanto, os entrevistados passaram a ser identificados com a letra "E" em maiúsculo, seguido de uma numeração e da denominação do hospital pelas letras A e B entre parêntese: (E 1, 2 - HOSP A, B) e assim sucessivamente.

Cada etapa dessa pesquisa foi conduzida a partir de critérios e de preceitos éticos emanados da Resolução n. 196/66 do Conselho Nacional de Saúde (CNS), o projeto dessa investigação foi submetido ao crivo de um Comitê de Ética da Pesquisa (CEP).

\subsection{Técnica de Coleta de Dados}

O trabalho de campo foi realizado no período de setembro a novembro de 2010. O instrumento de coleta de dados utilizado foi uma entrevista guiada por um roteiro semiestruturado.

A entrevista foi dividida em dois momentos: no primeiro momento foram realizadas perguntas fechadas e de igual conteúdo, preenchidas por meio da ficha de caracterização.
No segundo momento foram realizadas perguntas abertas, nas quais buscou-se identificar elementos que apenas seriam possíveis através da participação das pessoas e que fosse possível responder ao problema desta pesquisa.

\subsection{Técnica de Análise dos Dados}

O tratamento e a análise dos dados foram realizados após a transcrição das entrevistas. A transcrição dos dados foi organizada e os dados foram classificados para que se pudesse proceder ao tratamento para o qual utilizou-se a análise de conteúdo a partir da análise temática.

Na etapa da pré-análise foi realizada uma leitura minuciosa das entrevistas para perceber cada uma das falas e a maneira como elas eram colocadas $e$ exploradas ao longo do diálogo.

Quanto à exploração do material, essa etapa constituiu-se numa operação classificatória de maneira que fosse possível alcançar o núcleo de compreensão do texto. Então, foram criadas categorias que contemplassem cada representação e a partir da qual os conteúdos foram organizados.

As fases de leitura, de interpretação, de organização e de identificação dos dados resultaram na construção de duas categorias com quatro subcategorias para os entrevistados, membros da Equipe multidisciplinar e duas categorias com duas subcategorias para os Gestores. Nos Quadros 1 e 2 estão esquematizadas a estrutura das categorias de análise.

\begin{tabular}{|c|c|}
\hline Categorias & SubCATEGORIAS \\
\hline $\begin{array}{l}1 \text { - Concepção do } \\
\text { trabalho em equipe } \\
\text { multidisciplinar } \\
\text { de saúde }\end{array}$ & $\begin{array}{l}1.1 \mathrm{O} \text { trabalho em equipe } \\
\text { multidisciplinar exige coparticipação, } \\
\text { comunicação e interação. } \\
1.2 \mathrm{O} \text { papel de cada membro } \\
\text { na equipe multidisciplinar. }\end{array}$ \\
\hline $\begin{array}{l}2 \text { - O cotidiano do } \\
\text { trabalho das equipes } \\
\text { multidisciplinares } \\
\text { de saúde }\end{array}$ & $\begin{array}{l}2.1 \text { Rotina de trabalho das equipes } \\
\text { (reuniões, resolução de problemas). } \\
2.2 \text { Importância do papel de } \\
\text { cada membro da equipe. }\end{array}$ \\
\hline
\end{tabular}

Quadro 1: Categorias e subcategorias de análise - Equipe multidisciplinar

Fonte: Elaborado pelos autores deste artigo 


\begin{tabular}{ll}
\multicolumn{1}{c}{ CATEgORIAS } & \multicolumn{1}{c}{ SUBCATEGORIAS } \\
\hline $\begin{array}{l}\text { 1-Concepção do } \\
\text { trabalho em equipe } \\
\text { multidisciplinar de saúde }\end{array}$ & $\begin{array}{l}\text { Resolução de problemas } \\
\text { da unidade } \\
1.2 \text { Sugestões para o trabalho } \\
\text { em equipe na unidade. }\end{array}$ \\
$\begin{array}{ll}\text { 2- Avaliando o trabalho } \\
\text { e a interação da equipe } \\
\text { multidisciplinar de saúde }\end{array}$ & \\
\hline
\end{tabular}

Quadro 2: Categorias e subcategorias de análise - Gestores Fonte: Elaborado pelos autores deste artigo

\subsection{Ambiente de Pesquisa}

O campo de investigação foi constituído por organizações hospitalares mantidas pela iniciativa privada e/ou que participam do SUS, de forma complementar, por meio de contratos e convênios de prestação de serviços ao Estado, situadas no município de Salvador-BA.

Participaram deste estudo dois hospitais, a partir de duas situações: uma unidade de clínica médica e uma UTI geral de adulto, denominados aqui de Hospital A e Hospital B. O critério de inclusão desses cenários deve-se ao fato dessas organizações manifestarem interesse e que, portanto, aceitaram participar da pesquisa.

A organização A caracteriza-se como hospital geral, com esfera administrativa privada, com fins lucrativos e personalidade jurídica. Sua capacidade instalada é de 139 leitos. A CMC I foi escolhida por ser considerada uma unidade dinâmica que concentra, principalmente, pacientes que apresentam quadro grave, o que exige da equipe um elevado grau de complexidade na assistência. A unidade é composta por 21 leitos, com uma equipe diurna permanente composta por: dois enfermeiros; um de assistência e um líder, 11 técnicos de enfermagem, um fisioterapeuta que é designado conforme a necessidade de cada paciente e um nutricionista. O responsável direto pela parte administrativa da unidade é um enfermeiro, que assume a função de coordenador desta unidade e de mais duas, e um gerente de internação que é um enfermeiro responsável pela maioria das unidades de internação de todo o hospital.

A Organização B caracteriza-se como hospital geral, filantrópico, com esfera administrativa privada e personalidade jurídica. Sua capacidade é de 169 leitos, sendo que destes, 81 são conveniados ao SUS. A UTI foi selecionada pelo fato de ser a unidade que concentrava leitos na especialidade clinica médica, foco desta pesquisa. A unidade é composta por 14 leitos e mantém uma equipe permanente por plantão de 12 horas composto por: um médico plantonista, um médico diarista, um fisioterapeuta, um enfermeiro de assistência e seis técnicos de enfermagem. O responsável direto pela parte administrativa da unidade são dois enfermeiros, um assume a função de coordenação $e$ o outro assume a gerencia desta unidade.

\section{Revelando o trabalho e a gestão das EQUIPES MULTIDISCIPLINARES DE SAÚDE EM ORGANIZAÇÕES HOSPITALARES}

\subsection{Concepções e práticas de equipe multidisciplinar de saúde em organizações hospitalares na visão dos membros da equipe}

As categorias, subcategorias de análise e trechos de falas da equipe foram construídas a partir da liberdade e respeito dos diálogos proporcionados durante as entrevistas com os membros da equipe multidisciplinar de saúde.

\subsubsection{Primeira Categoria: concepção do trabalho em equipe multidisciplinar de saúde a partir da equipe}

O trabalho desenvolvido em equipe multidisciplinar de saúde indica a importância para o alcance de resultados. Para compreender esse aspecto, buscou-se conhecer as concepções dos membros da equipe acerca desse trabalho. Essa categoria apresenta as seguintes subcategorias: a) o trabalho em equipe multidisciplinar exige coparticipação, comunicação e interação da equipe multidisciplinar; b) o papel de cada membro na equipe multidisciplinar.

A subcategoria A: o trabalho em equipe multidisciplinar exige coparticipação, comunicação e interação da equipe multidisciplinar - Os entrevistados conceberam o trabalho em equipe 
como um conjunto de ações que exige coparticipação, comunicação e interação efetiva de seus membros, expressando assim um significado de trabalho conjunto e de "extrema importância"; já que o paciente não pode ser visto apenas como portador de uma patologia, mas como alguém que deve ser considerado em outras dimensões e, portanto, é necessário o entendimento de que a interação e a comunicação favorecem a troca de experiências; trazem conhecimentos; e resultam em aprendizagem organizacional.

[...] é um trabalho que você desenvolve com interação com todos os outros [...] dentro da competência de cada um [...]. (E 12 - HOSP B)

[...] exige a coparticipação de todos, [...] que se comunique e esteja interligado para que o trabalho flua [...]. (E 7 HOSP A)

Quanto à forma de se processar o trabalho em equipe, o entendimento dos entrevistados é semelhante ao que foi apontado como característica do trabalho em saúde por Colomé (2005) e Matumoto et al. (2005), assim como a importância da comunicação e da interação destacada por Peduzzi (1998; 2001) que, a partir da elaboração da tipologia do trabalho em equipe, contempla a existência de tais elementos na modalidade definida como equipe integração. A partir das concepções apresentadas, fica evidenciado que as equipes têm o entendimento de que no cotidiano é imperativa a existência dos elementos: comunicação $e$ interação efetiva.

A subcategoria B: o papel de cada membro na equipe multidisciplinar - Os entrevistados concebem o trabalho em equipe como a dimensão do objetivo único que deve ser resguardado por cada membro. De acordo com os entrevistados, cada um tem sua importância para que o trabalho se desenvolva de forma harmônica.

[...] cada um tem o seu papel [...], mas juntos, caminhando, aonde termina um, começa o outro [...]. (E 9 - HOSP B)

[...] é um trabalho que tem um fim, que é o paciente [...] cada um com a sua importância [...] tem seu momento de trabalho, de solução. (E 13 - HOSP B)
Esses aspectos ressaltados pelos entrevistados confirmam a concepção de autores como Merhy (1997) e Severo e Seminotti (2010) quanto à importância de cada profissional nas organizações, nos serviços e nas equipes de saúde, pois os profissionais estão em contato direto com o cliente/paciente no desenvolvimento diário de suas ações. Nesse sentido, é possível confirmar ainda o conceito de trabalho em equipe apresentado por Fortuna et al. (2005). Os autores entendem trabalho em equipe como um processo de relações que são construídas diariamente.

Destaca-se dentro dessa categoria a posição de um entrevistado que apresenta uma forma diferente e contraditória de conceber o trabalho em equipe; inicialmente há um reconhecimento de que todos os profissionais são muito importantes dentro das suas funções, para logo em seguida destacar os profissionais médico e enfermeiro como protagonistas e as "outras terapias" como coadjuvantes.

[...] cada um com sua função, mas todos muito importantes e fundamentais [...] que exige interação e que para o paciente é fundamental [...] (a equipe) multidisciplinar é importante mesmo, um não vive sem o outro, claro que tem o fundamental [...] o médico e a enfermagem são bem fundamentais, mas as outras terapias, assim, são coadjuvantes, mas fazem diferença. (E 11 - HOSP B)

Esse discurso da equipe multidisciplinar refuta conceitos de autores como Peduzzi (1998; 2001), Schraiber et al. (1999), Matumoto et al. (2005), Fortuna et al. (2005), quanto ao trabalho em equipe multidisciplinar e com relação aos elementos que contribuem para sua prática além do que pode desvelar a existência da relação de poder e de hierarquia no interior das equipes; o que corrobora ainda, conforme Schraiber et al. (1999), Fortuna et al. (2005), que essa é uma realidade vivida por essas equipes.

Portanto, embora seja perceptível que a maioria dos entrevistados aponte o reconhecimento do papel e do valor de cada membro na equipe, transparecem aspectos controversos que indicam a existência de sentimentos relacionados a tratamentos e valoração diferenciados a determinadas especialidades dentro das equipes. O que pode ser um indicativo da existência do poder vivenciado no cotidiano das equipes pesquisadas. 


\subsubsection{Segunda Categoria: o cotidiano do trabalho das equipes multidisciplinares de saúde}

Com o objetivo de identificar aspectos que refutam ou confirmam as concepções apresentadas pelos membros das equipes, buscou-se conhecer como se processa na prática o trabalho cotidiano dessas equipes. Essa categoria apresenta as seguintes subcategorias: a) rotina de trabalho das equipes; b) importância do papel de cada membro da equipe;

A subcategoria A: rotina de trabalho das equipes (reuniões, resolução de problemas...) - De acordo com os entrevistados, dentro das unidades onde se desenvolveu a pesquisa empírica, o contexto de trabalho é considerado bom, pois existem rotinas predeterminadas e uma boa relação interpessoal pensando num atendimento humanizado ao paciente.

[...] nós temos as nossas rotinas, a gente tenta seguir o que a empresa determina [...] nem sempre a gente consegue [...] porque tem sempre uma intercorrência [...] aí você acaba tendo que se adaptar [...]. (E $5-\operatorname{HOSP}$ A)

[...] não existe aqui, por exemplo, estrelismo, do médico não falar, do médico não sei o que, [...] uma relação muito boa [...] entre as equipes [...] claro que tem um colega ou outro, que num dia, pode se aborrecer e se exaltar [...], mas isso é do homem é da pessoa. (E 13 - HOSP B)

Há um reconhecimento dos entrevistados, quanto às especificidades das organizações hospitalares, que são reconhecidas como organizações complexas, por lidarem com situações que envolvem a vida humana, conforme evidenciadas por autores como Gurgel Júnior e Vieira (2002), Fortuna et al. (2005).

No momento em que os entrevistados afirmam que a rotina de trabalho dessas equipes é preestabelecida pelos hospitais, eles se contrapõem a posições de autores como Merhy (1997), Schraiber et al. (1999), Gariglio e Radicchi (2008) e Severo e Seminotti (2010). Eles afirmam que cabe à equipe construir conjuntamente o planejamento do seu trabalho, pensando no indivíduo como único, não cabendo, portanto, planejamentos prévios e fixos. Dessa maneira, ressalta-se a necessidade e a importância da participação da equipe na construção do planejamento como aspecto democrático e motivador; considerada a possibilidade de modificações em tempo real para atender às necessidades específicas, porém sem desconsiderar as rotinas e os procedimentos preestabelecidos que são resultantes do acúmulo de aprendizagens organizacionais.

No âmbito dessa subcategoria, destaca-se a fala de um entrevistado que entende a disponibilidade por parte dos membros da equipe para colaborar com o trabalho como consequência de uma norma do hospital e não como uma construção da equipe, contradizendo posicionamentos de autores como Merhy (1997), Eugênio Mendes (1999), Schraiber et al. (1999) e Fortuna et al. (2005), de que a equipe é como um processo de relações em constante construção, devendo sempre ser avaliado, de forma que o seu modo de trabalhar reflita situações conjuntas e reais.

De maneira geral, a equipe é solicita porque existe uma norma do hospital que é superior. Então, se eu precisar de alguém, ou se alguém precisar de mim, [...] e eu recusar tenho que dar uma justificativa do porquê [...]. (E 7 - HOSP A)

Os entrevistados foram unânimes ao afirmarem que as reuniões com a finalidade de estudar casos de patologias os quais a equipe acompanha não são uma realidade vivenciada na rotina; o que existe são reuniões científicas mensais com variedades de apresentações entre profissionais da mesma especialidade que fazem parte do quadro de funcionários do hospital, as reunióes direcionadas à enfermagem têm uma frequência também semanal.

Essas situações de reuniões multidisciplinares são ressaltadas por Fortuna et al. (2005) pelo fato de tais situações poderem significar momentos favorecedores para promoção do diálogo e da interação, mas podem também se deparar com contradições e com diferenças nem sempre expressadas objetivamente. Nessa pesquisa, não foi evidenciado pelas equipes que a reunião fosse uma meta da política organizacional, assim como não há o esforço próprio das equipes em estabelecer uma rotina de reuniões multidisciplinares.

[...] a empresa estimula muito o grupo de estudo [...] a equipe toda junta para se reunir é mais difícil [...] a maioria é mais direcionada para o enfermeiro [...]. (E 5 - HOSP A) 
[...] nós temos isoladamente seções, tanto da fisioterapia, como da enfermagem, como da minha equipe médica. Nós não temos uma seção única [...] são [...] separadas [...] (E 13 - HOSP B)

Os entrevistados consideram "complicada" a forma de a equipe atuar diante dos problemas cotidianos, isso porque neste momento as pessoas se expressam de diversas formas. Alguns entrevistados consideram que essa é uma questão resolvida de forma tranquila. Para outros, existem regras e medidas punitivas as quais são sempre sinalizadas, inicialmente pela coordenação, gerência e pela diretoria.

Tudo o que acontece independente do grau de dificuldade de resolubilidade [...] a gente tem uma coordenação onde tudo isso é passado [...]. (E 5 HOSP A)

Aqui as relações são bem hierarquizadas, verticalizadas, existem os níveis que temos que nos submeter. E nós ficamos limitados, [...] por mais [...] que eu leve os problemas para os membros da unidade que possam resolver o assunto, eles também têm os limites e precisamos realmente partir para hierarquia superior [...]. (E 8 - HOSP B)

Nesse contexto, o trabalho dessas equipes evidenciou que em alguns momentos de sua prática, de forma contraditória em relação às concepções inicialmente trazidas por cada membro da equipe, há o reconhecimento de que o planejamento, a organização e as rotinas do trabalho nem sempre acontecem como previstas. Isso devido à dinâmica e intercorrências cotidianas que, por vezes, as equipes necessitam modificá-las de forma individual e não como uma construção conjunta. A ideia inicial de que a equipe pode atuar conjuntamente para resolver seus problemas apresenta outra contradição, sobretudo quando há uma percepção de que a disponibilidade de cada um é imposta pelo hospital e que tudo deve ser repassado para a coordenação, o que evidencia a existência de limitação da autonomia da equipe.

A partir desse contexto, pode-se inferir que a comunicação e a interação nem sempre estão presentes no trabalho dessas equipes, pois, em alguns momentos, ambas acontecem de forma individual, trazendo o entendimento de que não haja unanimidade quanto à forma de gerenciamento dos processos ou insatisfação da forma como a equipe é gerida.

A subcategoria B: importância do papel de cada membro da equipe - Para os entrevistados, a definição do papel de cada membro da equipe é importante no cotidiano do trabalho, sendo necessário reconhecer o momento do seu limite de atuação profissional, e lançar mão do outro que naquele momento seja legalmente habilitado e capacitado.

Os entrevistados percebem, ainda, a atuação da enfermagem no atendimento ao paciente como "muito efetiva e forte"; uma vez que a enfermagem é a responsável pela assistência direta ao paciente durante 24 horas, sendo assim, quase sempre são os enfermeiros os primeiros que registram em prontuário na ocorrência de situações fora do previsto ou tomam outras atitudes com relação a elas.

[...] percebo que existe uma atuação muito efetiva da enfermagem, ela tem o papel do cuidado com o paciente muito forte, existe uma preocupação, muito grande em estar notificando [...] alguma reação fora do previsto [...]. (E 3 - HOSP A)

[...] em alguns momentos você tem que perceber que a sua função chegou a um limite e [...] lançar mão de um profissional que seja mais capacitado para lidar com [...] aquele problema [...]. (E 6 - HOSP B)

[...] o enfermeiro precisa estar sempre disponível, porque como ele está ali, ele é o centro, ele é uma referência [...] porque ele é o líder [...] ele gerencia [...] para poder [...] fazer esse tipo de trabalho [...] para que as coisas aconteçam. (E 5 - HOSP A)

Ressalta-se que o entendimento do profissional enfermeiro de que ele precisa "sempre" estar disponível para o trabalho em equipe multidisciplinar revela uma visão mais estreita em relação aos conceitos de autores como Merhy (1997) e Severo e Semiotti (2010) sobre equipe multidisciplinar e a forma como se desenvolve o seu trabalho. Pois, conforme esses autores, todos são responsáveis pelo modo de desenvolver o trabalho, de ocupar efetivamente seu espaço, de perceber como ele é planejado e gerido nos serviços e de produzir mudanças a partir da forma como se atua. 
Portanto, nesse momento entende-se que, embora haja um discurso de valorização e de importância de cada membro da equipe para o atendimento ao paciente, quando relatada a rotina, esse reconhecimento se expressa conferindo certo destaque ao papel do enfermeiro ou da equipe de enfermagem apontada como centro, a referência, e desconsiderando a importância e a responsabilidade dos demais membros.

\subsection{Concepções e práticas de equipe multidisciplinar de saúde em organizações hospitalares na visão dos gestores}

Como na seção 4.1, as categorias, subcategorias de análise e os trechos das falas dos gestores foram construídas seguindo o mesmo principio de liberdade e de respeito aos diálogos proporcionados durante as entrevistas com os membros da equipe multidisciplinar de saúde.

\subsubsection{Primeira Categoria: concepção do trabalho da equipe multidisciplinar de saúde na visão dos gestores de assistência}

Os gestores das organizações pesquisadas, aos quais as equipes estão diretamente subordinadas, conceberam o trabalho dessas equipes como de "suma" importância, responsabilidade e confiança, devendo ser desenvolvido de maneira interdisciplinar. Os entrevistados ressaltam ainda que sempre foi uma prioridade do hospital prestar um serviço de excelência, assim, eles se preocupam para que o atendimento prestado pelos profissionais componentes de seus quadros esteja alinhado aos valores organizacionais.

Essa concepção dos gestores acerca da equipe multidisciplinar, assim como da importância do seu trabalho nas organizações hospitalares, é evidenciada por autores como Scholtes (1992 apud SOUSA; CAMPOS; RAMOS, 2001) e Gurgel Junior e Vieira (2002).

[...] é de suma importância [...]. Nenhuma profissão, nenhuma especialização sozinha consegue, o enfermeiro não pode cuidar sem um médico para prescrever, por sua vez o médico não pode executar. [...] bem como a fisioterapia, nutrição [...]. (E 2 - HOSP A)
De responsabilidade, toda confiança, a parceria, todos os projetos, que são criados, são aprovados por eles então assim, é uma causa comum a todos. A gente busca fazer com que o serviço ande da melhor maneira possível, tanto para o nosso cliente externo, como para o nosso cliente interno que são os nossos funcionários. (E 3 - HOSP B)

Esses discursos se alinham às concepções dos subordinados sobre o trabalho em equipe nos aspectos de responsabilidade, interdisciplinaridade e, sobretudo, para a geração de resultados, a organização e para o paciente/cliente.

No trato dessa categoria, foram evidenciadas as seguintes subcategorias: a) resolução de problemas da unidade; $e$ b) sugestões para o trabalho da equipe na unidade.

A subcategoria A: resolução de problemas da unidade - Os gestores afirmam que a organização favorece a autonomia no cotidiano de trabalho de suas equipes, de modo que elas possam resolver internamente seus problemas, ressaltam que quando isso não é possível, os problemas são direcionados à coordenação, à gerência e à diretoria; no entanto, eles afirmam não existir impedimento para que as equipes possam apresentar suas demandas ou sugestões diretamente à direção, se assim desejarem. Ainda conforme os gestores, quando se objetiva resolver problemas da unidade, as suas "portas estão sempre abertas", eles destacam que o hospital tem como filosofia corrigir o erro e trabalhar para que esse erro não se repeta.

[...] os problemas são direcionados geralmente para mim, quando não há resolutividade, [...] quando é uma coisa que eu não consigo resolver é passado diretamente para gerência, [...]. (E10 - HOSP B)

Diretamente a porta não é fechada [...]. Nós temos essa filosofia, sempre foi uma política de que, o erro, a gente vai corrigir e trabalhar para que ele não se repita. Porque somos humanos, que lidamos com humanose com as suas famílias [...]. (E 2 - HOSP A)

O entendimento dos gestores sobre a importância das pessoas para essas organizações e sobre o tipo de serviço prestado está evidenciado em Colauto $e$ Beuren (2003). Quanto à autonomia entendida pelos gestores que é dada às equipes para a resolução de 
seus problemas, é destacada por Severo e Seminotti (2010) no modelo de gestão que valoriza a organização como importante espaço integrador e de formação profissional.

Nesse sentido, ressalta-se contradição entre o posicionamento dos gestores, ao informarem que a organização favorece a autonomia, e o que foi exposto anteriormente pela equipe, ao caracterizar a hierarquia do hospital como verticalizada, em que a equipe tem o poder decisorial limitado para resolver seus problemas. Além disso, relataram insatisfação do retorno às suas demandas.

Quanto à subcategoria B: sugestóes para o trabalho da equipe na unidade - Segundo os gestores, as equipes podem dar sugestões de maneira aberta, inicialmente são repassadas à coordenação e, quando se decide pela implantação, há um monitoramento pela equipe para avaliar se satisfaz às necessidades de trabalho da equipe e às do paciente.

Os gestores afirmam que, ao proporcionar abertura para sugestões da equipe, desenvolve-se um clima organizacional favorável para que todos possam fazer o melhor, que é atender bem ao paciente promovendo e restituindo a saúde para que a alta hospitalar aconteça o mais breve.

Eles passam diretamente para mim todas as ideias que eles têm, [...] eles têm que ver, se tem possibilidade de ser implantada [...], se tem possibilidades, se é uma coisa para o bem do paciente, [...], do serviço, [...] toda abertura a equipe tem. (E 10 - HOSP B)

De maneira, bem aberto. [...] a cada momento procura trabalhar com muita maturidade, para que a gente possa está fazendo o melhor não só para o meu trabalho, mas para o resultado final que é atender bem o paciente, promover e restituir a saúde para que ele tenha uma alta mais breve [...]. (E 2 - HOSP A)

É possível perceber que, sobre o aspecto "sugestões", existe um alinhamento no posicionamento dos gestores e dos membros da equipe confirmando que a organização reconhece a importância da participação e da contribuição da equipe para a melhoria dos serviços e do atendimento ao paciente, embora seja evidente que essa participação se restringe ao nível operacional.

\subsubsection{Segunda Categoria: avaliando o trabalho e a interação da equipe multidisciplinar}

Os gestores consideram importante a avaliação do trabalho da equipe, pois cabe a ela o atendimento direto ao paciente e a responsabilidade pela implementação do serviço diretamente relacionado à qualidade percebida, destacando que os gestores realizam uma avaliação informal e, percebida alguma "falha" do trabalhador, ele é chamado pelos gestores que avaliam o fato e, por uma proposta educativa, busca-se a correção do problema.

Ainda conforme os gestores, sistematicamente realiza-se uma avaliação formal, na qual se busca evidenciar gaps ou pontos de melhorias para o desenvolvimento do trabalho da equipe. Ressalta-se que no Hospital $\mathrm{B}$ não se evidenciou a realização desta avaliação.

De acordo com os gestores do Hospital A, anualmente são apresentados para a diretoria relatórios de todas as atividades de cada unidade de internação, no qual são destacados os principais resultados e o alcance das metas gerenciais, investimentos em processos/ qualidade, em ativos físicos, treinamento por equipe e por empregado. Os gestores informam ainda que a organização propõe que os coordenadores apresentem os resultados às suas equipes.

Você tem que avaliar para ver se o serviço está sendo bem feito, a busca é pela qualidade [...] para o bem-estar do doente [...] a partir do momento que se detecta alguma falha a gente tem que buscar a causa [...]. (E $3-H O S P B)$

[...] percebemos nas avaliações formais as coisas que podem ser trabalhadas, melhoradas [...]. [...] onde [...] percebe que algumas pessoas que tinham um potencial técnico maravilhoso, mas que o comportamento e até a comunicação estava muito difícil [...]. (E 2 - HOSP A)

Essa proposta dos gestores em apresentar os resultados para as equipes evidencia, ao que parece, o reconhecimento e a valorização do seu trabalho, assim como incentiva o sinergismo para que essas equipes possam superar de forma mais tranquila suas dificuldades e fragilidades, reconhecidas como elemento 
importante do trabalho em equipe, concordando assim com autores como Sousa, Campos e Ramos (2001).

Quanto à avaliação da interação na equipe, os gestores afirmaram que ela realiza-se informalmente, no dia a dia, eles percebem o momento das sessões científicas como oportuno para se mobilizar ações dessa natureza. Ainda conforme os gestores, as organizações desenvolvem a interação na equipe por perceberem a importância da coesão, que contribui tanto para a gestão quanto para o desenvolvimento do trabalho e o fortalecimento das relações interpessoais que geram maior comprometimento, satisfação e, consequentemente, melhor desempenho e favorecimento para a resolução de conflitos.

\section{[...] quando você tem um grupo coeso é muito} mais fácil, tanto a parte educacional para que eles possam trabalhar melhor, como a relação interpessoal que é muito importante [...] o rendimento é outro. (E 10- HOSP B)

\section{[...] eu acho que a gente tem um vínculo próximo} com os profissionais das diversas áreas, então tanto a parte administrativa, como a diretoria médica, [...]. A gente não vê dificuldade de entrar em contato com as pessoas e de ter um retorno imediato às demandas [...]. (E 1 - HOSP A)

No dia a dia a gente não tem maiores conflitos. Conflitos, eu acho que existe em qualquer instituição, mas são plenamente resolvidos, de forma amistosa [...]. (E 1 - HOSP A)

Essa posição dos gestores coaduna com Fortuna et al. (2005) e Merhy (1997) que entendem ser importante as relações interpessoais para o desenvolvimento do trabalho em equipe. Assim, é possível perceber a existência de um alinhamento com as falas dos membros da equipe quanto à existência de um ambiente que favorece a interação no seu interior, apesar de reconhecerem algumas dificuldades para desenvolver o trabalho relacionadas, por exemplo, a: questões de relações pessoais, interesses individuais, desconhecimento do trabalho em equipe, resistência por parte de alguns membros e relação de poder; tudo é relativizado e/ou minimizado quando está envolvido o atendimento ao paciente, "neste momento", o foco é o alcance do resultado e a solução do problema.

\section{Conclusão}

Ao concluir este trabalho, abordando o trabalho e a gestão das equipes multidisciplinares de saúde, com organizações hospitalares, a partir do referencial teórico e da realidade pesquisada passa-se a tratar das conclusões nos seguintes aspectos:

a) Das concepções sobre o trabalho em equipe multidisciplinar: analisando as concepções apresentadas pelos entrevistados, conclui-se que gestores e subordinados apresentaram suas concepções sobre os principais pontos do trabalho em equipe considerados essenciais, como: objetivo comum, multidisciplinaridade, coparticipação, comunicação, interação e reconhecimento dos papéis individuais no trabalho em equipe, que se assemelham e concordam entre si, demonstrando a existência de um alinhamento conceitual entre as duas categorias.

b) Do cotidiano do trabalho na equipe multidisciplinar: ao analisar o cotidiano do trabalho, constata-se que os membros das equipes entendem a importância de um ambiente favorável ao desenvolvimento do trabalho na medida em que relatam a maneira como eles desenvolvem suas atividades, destacando as rotinas das equipes, a importância da interdependência entre seus membros, a multidisciplinaridade $e$ a complementaridade; fatores estes apontados como garantidores do atendimento das necessidades do paciente/cliente e que proporcionam a ele a possibilidade de avaliar, apontar pontos fortes e fracos e gerar retornos para as equipes e para a organização.

c) Das relações de trabalho: ao analisar como se dão as relações de trabalho no contexto da equipe multidisciplinar, conclui-se que: a equipe reconhece a importância e a necessidade de cada especialidade para o atendimento ao paciente; a comunicação formal é instituída e atende satisfatoriamente às necessidades do trabalho, nesse sentido a equipe se comunica, interage e, de modo geral, discute a evolução do quadro de alguns pacientes. Ficou evidenciado que o ambiente de trabalho é propício do ponto de vista físico e operacional, porém, no que se refere às relações, elas são impactadas por: interesses pessoais e profissionais; difícil convivência entre especialistas; e relação de 
poder no interior da equipe. Acerca do problema de pesquisa, evidenciou-se a existência de ambiente favorável de trabalho, apesar de algumas divergências quanto à questão da operacionalidade das atividades. Destaca-se que o trabalho se desenvolve de forma ordenada a partir da presença de diversas especialidades que se complementam e participam das decisões e das sugestões nos aspectos operacionais.

Ao analisar a gestão da equipe multidisciplinar, percebeu-se a ausência de: uma atividade de gestão do trabalho em equipe multidisciplinar de forma proativa; uma política gerencial que preze pela igualdade entre os membros que a compõem sem o favorecimento da manutenção da supremacia de alguns profissionais em detrimento de outros; uma política de comunicação mais dinâmica que favoreça aos subordinados autonomia para atuar diante da resolução de problemas. Foi evidenciado ainda que, embora os gestores apresentem no seu discurso concepções que se alinham com o que define a literatura; na prática, esse alinhamento não acontece plenamente, pois eles permanecem presos a tabus e a tradições que, embora reconhecidos como negativos, são perpetuados.

Assim considera-se alcançado o objetivo proposto para o presente artigo, visto que os aspectos a serem analisados foram apresentados ao longo das conclusões. Porém, visando uma consolidação dos resultados em relação à equipe percebe-se que, embora as concepções e os posicionamentos apresentem alinhamento entre si e com o que concebe a literatura, constatou-se na prática do trabalho e da gestão a existência de aspectos considerados positivos que confirmam o discurso, como: ambiente favorável ao trabalho; rotinas das equipes bem estabelecidas e institucionalizadas, reconhecimento da interdependência e complementaridade entre os membros. Constatam-se também aspectos diferenciados que refutam o discurso: autonomia limitada para a resolução de problemas; interesses pessoais e profissionais que impactam na convivência entre profissionais; existência de relação de poder no âmbito das equipes; sentimento de tratamento diferenciado e privilegiado para determinada especialidade, o que denota negligenciamento do aspecto da multidisciplinaridade.

No que se refere aos gestores, eles também apresentam concepções e posicionamentos que se alinham entre si e entre a literatura nos aspectos de responsabilidade, multidisciplinaridade e, sobretudo, para geração de resultados; os gestores entendem que a organizaçao favorece autonomia para a equipe resolver no cotidiano os problemas que surgem; propiciam abertura para a equipe participar das sugestões e dos processos decisórios. Porém, na prática de gestão, apresentam-se dissonâncias em relação ao discurso como, por exemplo: não evidenciar o reconhecimento da relação de poder e tratamentos diferenciados e ausência de uma política estruturada que reflita um tratamento multidisciplinar do trabalho em equipe - que é tratado com visão reducionista de equipe, limitando-se aos agrupamentos de cada especialidade. Nesse sentido, as organizações hospitalares, que têm como característica atender à alta complexidade da saúde, precisam ainda mais de um ambiente efetivo de equipe multidisciplinar entendido de acordo com o que concebem membros da equipe e gestores. No entanto, conclui-se que a prática aos poucos vai se distanciando das concepções que eles elaboram. Portanto, para que haja efetivação entre discurso e prática faz-se necessário: romper com hierarquias rígidas que dificultem a autonomia; superar tabus e criar um processo de comunicação que respeite a liberdade de expressão e que favoreça a construção coletiva. Considerando que tais organizações apresentam satisfação com os atuais resultados do trabalho, mesmo considerando esses pontos negativos, é possível inferir que os seus resultados operacionais serão positivamente impactados a partir da melhoria da forma de desenvolvimento do trabalho e da gestão que, certamente, serão percebidos pelos clientes.

\section{REFERÊNCIAS}

BRASIL. Comitê Nacional de Ética em Pesquisa em Seres Humanos. Resolução n. 196, de 16 de outubro de

1996. Aprova as diretrizes e normas regulamentadoras de pesquisa envolvendo seres humanos, Brasília, DF, 1996.

CIAMPONE, Maria Helena Trench; PEDUZZI Marina.

Trabalho em equipe e trabalho em grupo no Programa de Saúde da Família. Revista Brasileira de Enfermagem, Brasília, DF, v. 53, n. especial, p. 143-147, dez. 2000. 
COLAUTO, Romualdo Douglas; BEUREN, Ilse Maria. Proposta para avaliação da gestão do conhecimento em entidade filantrópica: o caso de uma organização hospitalar. Revista de Administração Contemporânea, Curitiba, v. 7, n. 4, p. 163-185, out./ dez. 2003.

\section{COLOMÉ, Isabel Cristina dos Santos. Trabalho} em equipe no Programa Saúde da Família na concepção de enfermeiras. 2005. Dissertação (Mestrado) - Escola de Enfermagem, Universidade Federal do Rio Grande do Sul, Porto Alegre, 2005.

FEUERWEKER, Laura C. M.; SENA, Roseni R. Interdisciplinaridade, trabalho multiprofissional e em equipe. Sinônimos? como se relacionam e o que têm a ver com nossa vida? Olho Mágico, [on-line], Ano 5, n. 18, 1999. Disponível em: < http://www.ccs.uel.br/ olhomagico/N18/home.htm >. Acesso em: 5 jan. 2010.

FORTUNA, Cinira Magali et al. O trabalho de equipe no programa de saúde da família: reflexões a partir de conceitos do processo grupal e de grupos operativos.

Revista Latino-Americana de Enfermagem, Ribeirão Preto, v. 13, n. 2, p. 262-268, mar./abr. 2005.

GARIGLIO, Maria Terezinha; RADICCHI, Antônio Leite Alves. O modo de inserção do médico no processo produtivo em saúde: o caso das unidades básicas de Belo Horizonte. Ciência \& Saúde Coletiva, Rio de Janeiro, v. 13, n. 1, p. 153-163, 2008.

GURGEL JÚNIOR, Garibadi Dantas; VIEIRA, Marcelo Milano Falcão. Qualidade total e administração hospitalar: explorando disjunções conceituais. Ciência \& Saúde Coletiva, Rio de Janeiro, v. 7, n. 2, p. 325-334, 2002.

HARTZ, Zulmira M. de Araujo; CONTANDRIOPOULOS, Andre-Pierre. Integralidade da atenção e integração de serviços de saúde: desafios para avaliar a implementação de um "sistema sem muros". Cadernos de Saúde Pública, Rio de Janeiro, v. 20, supl. 2, p. S331-S336, 2004.

MATOS, Eliane; PIRES, Denise de Elvira Pires; CAMPOS, Gastão Wagner de Sousa. Relações de trabalho em equipes interdisciplinares: contribuições para a constituição de novas formas de organização do trabalho em saúde. Revista Brasileira de Enfermagem, Brasília, DF, v. 62, n. 6, p. 863-869, nov./dez. 2009.
MATUMOTO, Sílvia et al. Supervisão de equipes no Programa de Saúde da Família: reflexões acerca do desafio da produção de cuidados. Dossiê. Interface: Comunicação, Saúde, Educação, v. 9, n. 16, p. 9-24, set. 2004/fev. 2005.

MENDES, Eugênio Vilaça. Uma agenda para a saúde. 2. ed. São Paulo: Hucitec, 1999. (Saúde em Debate, 88)

MERHY, Emerson Elias. Em busca do tempo perdido: a micropolitica do trabalho vivo em saúde. In: ONOCKO, Rosana (Org.). Agir em saúde: um desafio para o público. São Paulo: Hucitec, 1997. p. 71-112.

Disponível em: <http://www.uff.br/saudecoletiva/professores/ merhy/capitulos-03.pdf> . Acesso em: 3 mar. 2010.

OLIVEIRA, Beatriz Rosana Gonçalves de; COLLET, Neusa. Relações de poderes (inter) profissionais e (inter) institucionais no Brasil. Revista Brasileira de Enfermagem, Brasilia, DF, v. 53, n. 2, p. 295-300, abr.jun. 2000.

PEDUZZI, Marina. Equipe multiprofissional de saúde: conceito e tipologia. Revista de Saúde Pública, São Paulo, v. 35, n. 1, p. 103-109, 2001.

Equipe multiprofissional de saúde: a interface entre trabalho e Interação. 1998. Tese (Doutorado) Faculdade de Ciências Medicas, Universidade Estadual de Campinas, Campinas (SP), 1998.

PINHO, Márcia Cristina Gomes de. Trabalho em equipe de saúde: limites e possibilidades de atuação eficaz. Ciência \& Cognição, Rio de Janeiro, v. 8, p. 68-87, 2006.

RICCARDI, Annie Lílian K. et al. O trabalho em equipe por meio de editor de texto coletivo. Novas Tecnologias na Educação, v. 7, n. 3, dez. 2009.

SCHRAIBER, Lilia Blima et al. Planejamento, gestão e avaliação em saúde: identificando problemas. Ciência e Saúde Coletiva, v. 4, n. 2, p. 221-242, 1999.

SEVERO, Silvani Botlender; SEMINOTTI, Nedio. Integralidade e transdisciplinaridade em equipes multiprofissionais na saúde coletiva. Ciência \& Saúde Coletiva, Rio de Janeiro, v. 15, supl. 1, p. 1685-1698, 2010.

SOUSA, Maria Quiteria. L de; CAMPOS, Ana Célia C. F; RAMOS, Rubens E. B. Trabalho em equipe: a base da qualidade nas organizações. Trabalho apresentado no XXIX Congresso Brasileiro de Ensino de Engenharia - COBENGE, 2001. 